\title{
LA DOCUMENTACIÓN DIPLOMÁTICA ENTRE LA CORONA DE ARAGÓN Y EL SULTANATO MAMELUCO DURANTE EL REINADO DE JAIME II: UN EJEMPLO DE LAS TRANSFORMACIONES EN LAS RELACIONES INTERNACIONALES DEL ÁMBITO MEDITERRÁNEO EN LA BAJA EDAD MEDIA
}

\section{Gabriel GONZÁLEZ MAURAZOS}

El tema que se pretende abordar en esta comunicación es de capital importancia para conocer los orígenes de las relaciones entre la Corona de Aragón y los Estados islámicos mediterráneos durante la Baja Edad Media. Es una cuestión que ya ha sido abordada por la historiografía contemporánea, si bien ha interesado más a arabistas e historiadores dedicados al estudio de Oriente Medio en época medieval (Heyd ${ }^{1}$, Aziz Suryal Atiya ${ }^{2}$, Labib ${ }^{3}$, Irwin $^{4}$, Holt $^{5}$ ) que a medievalistas especializados en la Corona de Aragón y su expansión territorial y comercial por el Mediterráneo.

La documentación que ha sido utilizada para realizar este estudio es aquella que se halla en el Archivo de la Corona de Aragón y que ha sido publicada, bien de forma íntegra, bien de manera resumida, por Capmany ${ }^{6}$, Aziz Suryal Atiya ${ }^{7}$, y Alarcón y Santón y García de Linares ${ }^{8}$. Cada autor se dejó llevar por diferentes criterios a la hora de

1 Histoire du commerce du Levant au Moyen Âge, II, pp. 30 y ss.

2 Egypt and Aragon. Embassies and Diplomatic Correspondence between 1300 and 1330 A.D.

3 Handelsgeschichte Ägyptens im Spätmittelalter, pp. 78-80.

4 The Middle East in The Middle Ages: The Early Mamluk Sultanate, 1250-1382, pp. 73-74, 9899 y 117.

5 The Age of The Crusaders, p. 166.

6 Antiguos tratados de paces y alianzas, pp. 26-35.

7 Op. cit.

8 Los documentos árabes diplomáticos del Archivo de la Corona de Aragón, pp. 335-368. 
elaborar sus colecciones documentales. Así, frente al criterio filológico seguido por Capmany (recoge la correspondencia que, escrita en catalán por los monarcas aragoneses, fue dirigida a los soberanos de los principales Estados islámicos bajomedievales del Mediterráneo), o por Alarcón y Santón y García de Linares (complementan el trabajo de Capmany al recopilar las cartas que los jefes de Estado del Islam remitieron en lengua árabe a varios monarcas hispánicos), se opone el criterio cronológico empleado por Aziz Suryal Atiya, quien estudia las relaciones diplomáticas entre el Sultanato mameluco y la Corona de Aragón durante el período 1300-1330, en el que se registran un total de ocho embajadas. Se trata de un encuadre puramente formal y arbitrario, pues no se ajusta a ninguna realidad política o documental: no se incluye la actividad diplomática de los primeros años del reinado de Jaime II, desarrollada a finales del siglo XIII, y, por contra, se añaden las embajadas de 1328 y 1330, ya en tiempos de Alfonso IV. El período 1300-1330 tampoco es significativo desde el punto de vista mameluco, pues esta primera actividad diplomática con la Corona de Aragón se desarrolla básicamente a lo largo de los tres sultanatos de al-Nasir Muhammad, esto es, entre los años 1293 y 1341 , si bien existe correspondencia anterior. Por tanto, para conocer la génesis de las relaciones diplomáticas entre la Corona de Aragón y el Sultanato mameluco, es preciso tener en consideración la documentación producida en la última década del siglo XIII.

Los trece textos que han sido utilizados para llevar a cabo este estudio han sido todos ellos publicados por los tres autores anteriormente citados. Redactados entre los años 1292 y 1328, componen en su conjunto una secuencia documental, que puede estar incompleta, a juzgar por los grandes paréntesis temporales en los que hay un vacío documental, así como por la alusión que en algunos de ellos se hace a la correspondencia recibida por alguna de las partes pero que hoy nos es desconocida. En cualquier caso, dicha secuencia responde siempre a la misma tónica: el desarrollo de un intercambio de correspondencia entre el monarca aragonés y el sultán mameluco. Cuando sea el primero quien tome la iniciativa a la hora de establecer relaciones diplomáticas con el segundo y solicitarle una serie de concesiones, el soberano musulmán responderá positivamente a las embajadas de Jaime II y en la mayoría de los casos satisfará los ruegos del rey Justo, aunque, recíprocamente, también utilizará el envío de misivas como medio para obtener del monarca aragonés una serie de bienes y privilegios.

No deja de llamar la atención el hecho de que estas iniciales relaciones diplomáticas entre la Corona de Aragón y el Sultanato mameluco estén prácticamente asociadas a las figuras de Jaime II y al-Nasir Muhammad, si bien hay noticias de embajadas anteriores a estos soberanos ${ }^{9}$, al igual que sabemos que hay una continuidad en la actividad diplomática tras la muerte de Jaime II, como atestigua el intercambio de

9 De hecho, las cartas fechadas en 1292 corresponden a embajadas desarrolladas en tiempos del sultán al-Ashraf Khalil. Además, en la carta que el sultán dirige a Jaime II el 9 de agosto de 1292 se menciona la existencia de unas relaciones anteriores entre ambas naciones, siendo rey Alfonso III (véase CAPMANY, Op. cit., p. 27). 
correspondencia que continúa desarrollándose entre Alfonso IV y al-Nasir Muhammad ${ }^{10}$. A continuación, se enumeran por orden cronológico las cartas publicadas que han sido utilizadas para realizar la presente comunicación:

1. 28-I-1292. ACA, carta árabe $n^{\circ}$ 153. En Alarcón y Santón y García de Linares (original árabe y traducción al castellano), pp. 335-344.

2. 9-VIII-1292. En Capmany (traducción castellana del original catalán), pp. 26-31.

3. 6-IV-1300. ACA, carta árabe en papel. En Atiya (extracto del original árabe con traducción al inglés), pp. 17-19.

4. 1-VI-1303. ACA, reg. 334. En Atiya (fragmentos del original catalán), pp. 20-21.

5. 19-V-1304. ACA, cartas árabes. Rollo II. En Alarcón y Santón y García de Linares (original árabe y traducción al castellano), pp. 350-354; y Atiya (extracto del original árabe con traducción al inglés), pp. 22-24.

6. 1-IX-1305. ACA, reg. 334. En Atiya (fragmentos del original catalán), pp. 26-27.

7. 16-1I-1306. ACA, cartas árabes. Rollo IV. En Alarcón y Santón y García de Linares (original árabe y traducción al castellano), pp. 355-360; y Atiya (resumen del contenido y edición de una lista de regalos ofrecidos por el sultán a Jaime II, que fueron enviados a Barcelona desde Egipto en esta embajada), pp. 28-32.

8. 8-IX-1314. ACA, reg. 337, fol. 231. En Atiya (fragmentos del original catalán y resumen del contenido), p. 35; y Capmany (traducción castellana del original catalán), pp. 32-35.

9. 17-III-1315. ACA, cartas árabes. Rollo I. En Alarcón y Santón y García de Linares (original árabe y traducción al castellano), pp. 360-365; y Atiya (texto árabe y su traducción al inglés), pp. 36-41.

10. 27-VIII-1318. ACA, reg. 337, fol. 233. En Atiya (sólo se resume su contenido), pp. $42-43$.

11. IX-1322. ACA, reg. 338 , fol. 138. En Atiya (texto catalán original), p. 45.

12. 23-II-1323. ACA, cartas árabes. Rollo VI. En Alarcón y Santón y García de Linares (original árabe y traducción al castellano), pp. 365-368; y Atiya (texto árabe y su traducción al inglés), pp. 47-52.

13. 20-VIII-1327. ACA. Regesta Jacobi, II, reg. 338 , fol. 140. En Atiya (texto catalán original), pp. 53-54.

Para iniciar el estudio de estas trece cartas, se pueden agrupar en tres fases cronológicas, utilizando como criterios divisorios los períodos de silencio documental. No obstante, conviene señalar que los temas contenidos en la documentación son bastante homogéneos, por lo que este tipo de clasificación respondería únicamente a la intención de dar una posible explicación a la ausencia de embajadas por una u otra parte en determinados momentos históricos.

10 Son un ejemplo de esto los documentos árabes de 1328 (véase ATIYA, Op. cit., pp. 57-60; ALARCÓN Y SANTÓN y GARCÍA DE LINARES, Op. cit., pp. 368-370) y 1330 (véase Suryal ATIYA, Op. cit., pp. 61-65; ALARCÓN Y SANTÓN y GARCÍA DE LINARES, Op. cit., pp. 370-371). 
Una de esas preocupaciones que está siempre presente en todas las embajadas es el deseo que ambas naciones tienen de mantener los lazos de amistad establecidos a finales del siglo XIII; unos vínculos que pueden buscar como meta el reconocimiento mutuo como potencias y representantes ante el otro de la Cristiandad y el Islam respectivamente. Es por esta razón por lo que la principal preocupación reflejada en la documentación va a ser la seguridad de los súbditos residentes en el territorio de la otra potencia. Un deseo que irá dirigido hacia la protección de los comerciantes, pero, en el caso de Jaime II, se hará con el fin de garantizar el ejercicio del culto cristiano en las ciudades del Sultanato mameluco, así como el acceso a los Santos Lugares por parte de los peregrinos y el derecho a la Iglesia occidental a compartir el Santo Sepulcro con otros ritos cristianos. Por tanto, es evidente que, mientras Jaime II pretende mostrarse como protector de los cristianos orientales que habitan las ciudades del Sultanato mameluco y principal defensor de los intereses de la Iglesia latina en Tierra Santa, la postura adoptada por al-Nasir Muhammad es la de un líder panislámico que considera como su deber la salvaguarda del bienestar de todos los musulmanes, incluidos aquellos que se hallan bajo el dominio de una autoridad cristiana, como es el caso de los mudéjares de la Corona de Aragón: "Hegemony over the rest of the Muhammadan world is here re-claimed for Egypt ${ }^{11}$.

En definitiva, podemos afirmar que con este tipo de política se abre una nueva etapa en las Relaciones Internacionales del mundo mediterráneo medieval: tras una fase de dos siglos de confrontación militar entre la Cristiandad y el Islam en Oriente Medio, motivada por el fenómeno de las Cruzadas, se asiste, tras la toma por las tropas mamelucas de las últimas plazas cruzadas en la costa mediterránea oriental (Acre es conquistada en 1291), a un nuevo período histórico, que se caracterizará por un dominio mameluco en Oriente Medio, incuestionable por los Estados de Europa occidental, que ahora tratarán de acercarse a esta potencia islámica a través del envío de embajadas.

\section{LAS ETAPAS DE LAS RELACIONES EGIPCIO-ARAGONESAS EN EL REINADO DE JAIME II}

\section{Los documentos de 1292}

Entrando ya en el análisis de cada una de las fases en que hemos dividido a la documentación, se puede considerar como primera fase aquella compuesta por las dos primeras cartas, ambas de 1292, las únicas pertenecientes al siglo XIII y ocho años anteriores a la siguiente, que data de 1300 . Pese a poderse tratar del comienzo de las relaciones entre ambas potencias, la carta del 9 de agosto hace referencia a una embajada anterior de Alfonso $1 \mathrm{II}^{12}$. Es posible que ésta se produjera en 1291, poco antes de su muerte, y que la carta que el sultán (en ese momento lo era al-Ashraf

11 ATIYA, Op. cit, p. 52.

12 CAPMANY, Op. cit., p. 27. 
Khalil) dírigió a Jaime II fechada el 28 de enero de 1292, fuese una contestación a la misiva inicial de Alfonso III.

Lo más destacado de esta etapa de las relaciones bilaterales mantenidas entre Egipto y Aragón, protagonizadas en el lado aragonés por los emisarios Romeo de Marimón y Raimundo Alemany, es el espíritu de liderazgo que ya se observa en Jaime II, al incluir a Castilla y Portugal, cuyas casas reales están unidas a la aragonesa por lazos matrimoniales, en los tratados de paz y amistad con los mamelucos. Se establecerá también un pacto contra el rey de Francia, manifestándose con esto lo que va a resultar evidente en la documentación posterior: la pugna que ambas monarquías europeas van a establecer por ser reconocidas como potencias cristianas protectoras de los Santos Lugares y las comunidades cristianas que viven bajo el dominio mameluco. Por ese motivo se desarrollará una intensa actividad diplomática encaminada al reconocimiento por parte del sultán de tal autoridad a una u otra nación.

\section{El período 1300-1306}

La primera carta de cuantas conservamos de esta serie es la que con fecha de 6 de abril de 1300 el sultán al-Nasir Muhammad dirige a Jaime II, si bien menciona en esta misiva una embajada anterior realizada por el monarca aragonés a Egipto, de la que no tenemos constancia documental ${ }^{13}$. Junto al siempre presente deseo de seguridad y bienestar que Jaime II manifiesta a lo largo de todo su reinado para los súbditos aragoneses que habitan o visitan el pais mameluco, se pueden observar una serie de elementos y características comunes en la correspondencia realizada entre los años 1300 y 1306 que nos permiten observar que estamos ante un conjunto de embajadas que integran un ciclo propio dentro de toda la documentación quę estamos analizando.

No obstante, la embajada que al-Nasir envía a Jaime Il en 1300 pone de manifiesto un fenómeno que se está produciendo en Oriente Medio en este momento y que hace que esta carta del sultán de El Cairo tenga un contenido especial: el avance de los mongoles hacia el oeste, que va a poner en jaque el dominio mameluco de Siria, una región que es invadida por las tropas del ilján de Persia Ghazan a finales de 1299, y aunque los mamelucos recuperaron ese territorio en primavera, hoy parece claro que «for a brief period, some four months in all, the Mongol il-khân was de facto the lord of the Holy Land»" ${ }^{14}$. Esta "conquista" de Tierra Santa por los mongoles es convertida inmediatamente por las naciones de Europa occidental en una recuperación del Reino de Jerusalén para la Cristiandad, al haber sido arrebatado de las manos del Islam por Ghazan ${ }^{15}$. Por este motivo, el sultán mameluco tratará de volver a poner de su parte a las potencias cristianas, lanzando una campaña propagandística en la que anuncia sus campañas victoriosas contra el ilján de Persia ${ }^{16}$. No obstante, Jaime II se

13 ATIYA, Op. cit, p. 18, nota 1.

14 SCHEIN, «Gesta Dei per Mongolos 1300», p. 810.

15 lbidem, p. 805

16 lbidem, p. 810, nota 5; ATIYA, Op. cit., p. 17, nota 3. 
dejará llevar por esa corriente de pensamiento que fluye por todo el Occidente europeo y que considera a Ghazan como el conquistador de Jerusalén para la Cristiandad, por lo que escribe al ilján una carta fechada el 19 de mayo de $1300^{17}$, en la que «desea saber, si quiere ayuda suya, qué parte le dará de la Tierra Santa, que mediante la gracia de Dios nuestro Señor ha ganado nuevamente, y de aquella que en adelante ganare y conquistare ${ }^{18}$. De nuevo, queda patente el interés que el monarca aragonés tiene por Tierra Santa, dado el poder y prestigio que da su control de cara al resto de la Cristiandad.

Una vez normalizada la situación en Siria, con la recuperación del control del territorio por parte mameluca, se seguirá la rutina habitual en la correspondencia diplomática entre Egipto y Aragón. El protagonista por parte aragonesa de este ciclo de embajadas es Aymeric Dusay, que va a protagonizar un desafortunado suceso con el embajador mameluco Fahr al-Dîn en el puerto de Alejandría en 1306, ocasionado por la retención de uno de los rehenes cristianos que iba a ser liberado y embarcado rumbo a Barcelona ${ }^{19}$. La respuesta del sultán será el arresto inmediato de todos los aragoneses instalados en Alejandría, lo que será considerado por Jaime II un motivo suficiente para romper las relaciones diplomáticas, puesto que una de las peticiones formuladas por el monarca aragonés en aquella embajada, recogida en la carta fechada el 16 de febrero de 1306, era que se garantizase la seguridad de los mercaderes aragoneses asentados en ese puerto egipcio.

Esto será lo más destacado de esta fase en las relaciones egipcio-aragonesas, junto a la exclusión de Castilla y Portugal en los tratados. Parece ser que Aragón pierde a comienzos del siglo XIV representatividad en el marco ibérico, a juzgar por una carta que en 1300 al-Nasir envía a Alfonso XI de Castilla (realmente el monarca es Fernando IV, pues es el período de la minoría de edad de Alfonso), en respuesta a una misiva remitida por el rey castellano. A partir de este momento, las embajadas de Jaime II al sultán mameluco representarán exclusivamente a la Corona de Aragón.

\section{El período 1314-1327}

El grave incidente ocurrido en 1306 en Alejandría, unido a la deposición de al-Nasir Muhammad por al-Muzzafar Baybars II, ahora nuevo sultán (1308-1310), hace que se enfríe la relación diplomática que es objeto de nuestro estudio.

Sin embargo, en los años siguientes se van a producir dos acontecimientos que van a propiciar la restauración de este intercambio bilateral de embajadas. En Oriente, el retorno al poder de al-Nasir Muhammad en el que va a ser su tercer sultanato (13101341), hace que la más poderosa nación del Levante mediterráneo esté gobernada de nuevo por un jefe de Estado deseoso de ser considerado líder de Dâr al-Islâm, tanto por todos los musulmanes del mundo como por las potencias europeas.

17 Traducida por CAPMANY, Op. cit., pp. 106-109.

18 lbidem, p. 108.

19 Sobre este suceso, véase ATIYA, Op. cit., pp. 33-34. 
Mientras, por parte aragonesa se produce, en 1315, el matrimonio de Jaime II con María de Lusignan, de la casa reinante en Chipre, siendo éstas las terceras nupcias del monarca aragonés. Este enlace concede aún más fuerza al ya importante papel que jugaba Jaime II en el Mediterráneo oriental, «for Marie was a potential heiress to Cyprus and Jerusalem ${ }^{20}$, aunque posteriormente fuera desheredada en favor de uno de sus sobrinos.

Es muy posible que esta nueva situación haga plantearse a Jaime II la posibilidad de reemprender las relaciones con al-Nasir Muhammad. De hecho, un año antes de su matrimonio con la presumible heredera al trono chipriota, en 1314, decide recuperar la amistad del sultán mameluco a través del envío de una embajada que es contestada favorablemente por al-Nasir el 13 de marzo del año siguiente; muestra del agrado con que acoge la iniciativa aragonesa es la lista de regalos, fundamentalmente de carácter textil, incluida en su carta ${ }^{21}$, que es una interesante muestra de los más destacados productos de la industria de lujo mameluca.

En definitiva, se ha abierto una nueva etapa en las relaciones de amistad que Jaime II siempre quiso establecer con los sultanes de El Cairo; una nueva época en la que el rey Justo no contará con un único emisario como en el ciclo anterior, sino que serán distintos los nombres que se registren en la documentación. Sólo el nombre de Arnaldo Sabastida aparecerá en dos de las embajadas (1314 y 1318), y nunca solo, sino acompañado por otro emisario (Guillem de Casanadal y F. de Villafrancha respectivamente). El resto de emisarios serán Berenguer de Castro y Gerardo de Olivaria (embajada de 1322) y Pere de Mijavila (1327). Mediante esta política, es posible que Jaime II pretendiera evitar que los embajadores acumularan un excesivo poder, que les pudiera permitir actuar en función de sus intereses, como pudo llegar a suceder con Aymeric Dusay.

Sin embargo, la cuestión más sobresaliente de este período es de nuevo de índole religiosa, relacionada con el control de los Santos Lugares, amén de la petición de traslado a España de determinadas reliquias; una actitud que no gustó a los cristianos orientales y que fue considerada como un abuso de influencia por parte de Jaime $\mathbf{I}^{22}$. El principal interés que en estos momentos tiene el monarca aragonés sobre Tierra Santa es el control del Santo Sepulcro mediante el encargo de la custodia de este importante lugar sagrado de la Cristiandad a monjes pertenecientes a la Corona de Aragón. Así, en la carta de 1322, solicita la custodia de esta iglesia jerosolimitana para los monjes Dominicos aragoneses, si bien en 1327 los favores del monarca irán dirigidos hacia los Franciscanos ${ }^{23}$.

Sin embargo, la suerte de Jaime II con respecto al control de Tierra Santa pudo haber cambiado ese mismo año, ya que su embajada coincidió en Egipto con una francesa que contaba con la sanción del Papado para representar a la Cristiandad

20 BISSON, The Medieval Crown of Aragon, p. 95.

21 ALARCÓN Y SANTÓN y GARCÍA DE LINARES, Op. cit, pp. 364-365.

22 Sobre el intento aragonés de trasladar reliquias como el cuerpo de Santa Bárbara, véase ATIYA, Op. cit, pp. 44-47.

23 Ibidem, p. 53. 
ante el sultán. Cuando todo parecía que iba a decantarse en favor del rey de Francia, la habilidad de Mijavila, el embajador aragonés, permitió que al-Nasir cambiara de opinión y Jaime II siguiera manteniendo su posición de liderazgo sobre los Santos Lugares y de portavoz de la Cristiandad ante el Sultán. De esta manera quedaba abierto el camino para el futuro monarca aragonés, Alfonso IV, que continuaría con esta política de amistad hacia el sultanato mameluco, tan brillantemente desarrollada por su padre.

\section{CONCLUSIONES}

A lo largo de la presente comunicación hemos analizado los principales puntos que configuraron las relaciones diplomáticas establecidas entre Jaime II de Aragón y los sultanes mamelucos contemporáneos a aquél. Unas relaciones que realmente no son más que uno de los muchos ejemplos registrados de intercambios bilaterales de correspondencia entre potencias del Occidente europeo y el Islam.

Tras la intervención bélica en el Oriente mediterráneo por parte de las naciones del Occidente latino a través de las Cruzadas en los siglos XII y XIII, se llega al surgimiento de un poder islámico eficaz a mediados de esa última centuria: es el Sultanato mameluco Bahrî, que para 1291 ha conseguido arrebatar a los cristianos occidentales todos los territorios de Oriente Medio que estaban en su poder.

La derrota militar obliga a las naciones europeas a buscar otros medios para seguir estando presentes en Oriente, y ello, unido al deseo que los propios mamelucos tienen de establecer contacto con esas naciones para poder cubrir algunas de sus necesidades, impulsará el desarrollo del intercambio de embajadas.

Las relaciones diplomáticas que la Corona de Aragón mantendrá con Egipto serán especialmente intensas pues ambos Estados tienen los ingredientes que les hacen ser mutuamente atractivos: la Corona de Aragón, a través de su expansión mediterránea, se ha convertido en una potencia; de ahí que desee ser influyente en el Mediterráneo oriental, donde ahora cuenta con importantes intereses. Por otro lado, la Corona de Aragón es un Estado que cuenta con una importante población musulmana sometida al dominio cristiano, lo que no deja indiferente al sultán al-Nasir, en su deseos de ser reconocido como líder del Islam por el resto del mundo musulmán. En lo económico, la necesidad que tiene el Sultanato mameluco de barcos y metal, elementos indispensables para una sociedad guerrera, pero de los que carece, impulsa a Egipto a aproximarse a la Corona de Aragón que posee hierro en abundancia y es una potencia naval.

Todas estas necesidades hacen que estos lazos de amistad fragüen pronto y siempre esté presente el deseo de mantenerlos por parte de ambos Estados, dado el beneficio mutuo que ello les conlleva. En ese sentido, estamos sólo ante uno de los varios ejemplos de las nuevas actitudes adoptadas entre Estados cristianos e islámicos dentro del marco mediterráneo. 


\section{BIBLIOGRAFÍA}

ALARCÓN Y SANTÓN, M.A. y GARCÍA DE LINARES, R., Los documentos árabes diplomáticos del Archivo de la Corona de Aragón, Madrid-Granada, 1940.

ATIYA, Aziz Suryal, Egypt and Aragon. Embassies and Diplomatic Correspondence between 1300 and 1330 A.D., Leipzig, 1938.

BISSON, T.N., The Medieval Crown of Aragon. A Short History, Oxford, 1986.

CAPMANY Y MONTPALAU, Antonio de, Antiguos tratados de paces y alianzas entre algunos reyes de Aragón y diferentes príncipes infieles de Asia y África, desde el siglo XIII hasta el XV, Madrid, 1786 (reimpr. facsímil: Valencia, 1974).

HEYD, W., Histoire du Commerce du Levant au Moyen Âge, 2 vols., París, 1885-86. HOLT, P.M., The Age of the Crusaders: The Near East from The Eleventh Century to 1517, Nueva York, 1986.

IRWIN, Robert, The Middle East in The Middle Ages: The Early Mamluk Sultanate, 1250-1382, Londres, 1986.

LABIB, Subhi Y., Handelsgeschichte Ägyptens im Spätmittelalter (1171-1517), Weisbaden, 1964.

SCHEIN, Silvia. "Gesta Dei per Mongolos 1300. The Genesis of a Non-event", The English Historical Review, XCIV (1979), pp. 805-819. 